\title{
Relationship between Organization Culture and Managers' Performance: Empirical Study of a Chinese University
}

\author{
Yu Sing Ong
}

Dr, Professor, HELP University, Malaysia

Wang Yue

Deputy Director, International Cooperation and Exchange, Guilin University of Electronic Technology, China

\begin{abstract}
This study investigated the relationships between organizational culture and managers' performance in a Chinese university, with commitment as a mediating variable. It revealed that organizational culture had a significant impact on commitment of employees. At the same time, commitment impacted managers' performance positively. However, the study also highlighted that organizational culture had no significant impact on performance, contradicting many past studies on the impact of organizational culture on performance. The authors developed a framework adapting the four dimensions of organizational culture based on Denison Organizational Culture Survey (DOCS). They also adapted the three dimensional concept of organizational commitment developed by Allen \& Meyer, characterized by affective, continuance and normative commitment. The authors decided to investigate the contextual performance rather than task performance as it relates to spontaneous behavior, organizational citizenship behavior, pro-social behavior and dedication to the spirit of organization. While contextual performance does not contribute directly to organizational performance unlike task performance, it nevertheless, enhances the psychological and social aspects of the organization. They have also adapted the performance measurement scale developed by Scotter $\&$ Motowidlo as a measure for contextual performance. Chinese universities are unique as most of the top leaders are appointed by the central government. Major challenges arise for university leaders as they face competition both locally and abroad to raise the academic ranking of their institutions. The study suggested changing the governance structure of universities to meet the rising demands for greater autonomy and flexibility from academics and administrators. A more diversified system of higher education institutions is needed to cater to different demands within the higher education system at large. As such, each institution will have to develop its unique organizational culture to ensure its sustainability.
\end{abstract}

Keywords: university culture, performance, commitment, China.

JEL Classification: M14, L1.

(C) The Authors, 2018. This article is published with open access at Sumy State University.

\section{Introduction}

In 2017, China had 2,914 colleges and universities, comprising of 2,631 universities (including 265 private higher education institutions). There were 793 postgraduate training institutions, consisting of 576 universities and 217 scientific research institutes (MOE China, 2018). The popularization of higher education is a key to China's economic growth. At the same time, it helps to reduce the disparity in developmental growth between the different regions.

Universities are complex social organizations with a distinctive type of organizational culture shaped by the continuous interactions between academics, administrators, staff, students, and government (McNay, 1995; Jameson, 2011). University's organizational culture is a key determinant of the success of a university. At present, China's universities are actually a typical model of executive power. The university organizational culture model is dominated by bureaucratic mode and influenced by China's political system. Zhang (2009) noted that the reform policies in Chinese universities have focused on the surface level of organizational culture while the deeper levels are left intact. Much research has been done on university organizational culture in Western developed countries, but insufficient studies have been conducted on the same topic in China.

Organizational commitment is an important concept in contemporary organizational behavior and human resource management. The impact of organizational commitment on employee performance has attracted much attention in business management and public management. Much research has been done on the 
commitment of university members. Attributes such as job satisfaction, organizational commitment, and psychological contract directly affect employee performance (Guan et al., 2014; Li et al., 2017).

The commitment of middle level managers is important to produce the best possible outcomes for their learners and their stakeholders. Deans and heads of departments have the responsibility to help staff members to adapt to any changes in institutional priorities. Research on deans and their leadership commitment and performance is sparse. Middle level managers should possess good problem-solving skills in addition to good interpersonal skill and be resilient under difficult circumstances. As academic leaders, they need to be equipped with the necessary competencies to perform their leadership roles (Shahmandi et al., 2011). There is a gap in the existing literature regarding relationships between organizational culture and middle level managers' performance in Chinese universities settings.

The purpose of this study is to investigate the relationship between the organizational culture and middle level managers' performance with commitment as a mediating variable in a Chinese university. From the findings of the study, the authors suggested the governance structure of universities be remodeled to accommodate the demands for greater autonomy from academics and administrators.

\section{Literature Review}

\subsection{Organization Culture}

Tierney (1988) defined organizational culture as a force that is derived from the values, processes, and goals held by those most intimately involved in the workings of the organization. It is manifested through language, symbols, rituals, values, beliefs and behavior. Culture plays an important role in the organization's performance. A supportive organization culture motivates employees to perform more productively (Ritchie, 2000). Organizational culture has a positive and significant relationship on organizational commitment and employee performance (Hakim, 2015). Changes need to be made in the organizational culture to make employees more committed to their organizations by implementing strategies that are mutually beneficial to employees (Dwivedi et al., 2014).

Denison (1990) developed the Denison Organizational Culture Survey (DOCS), which comprises four dimensions of organizational culture: adaptability, mission, involvement and consistency. Each of these four components corresponds to three sub-dimensions, and each sub-dimension consists of five more specific indicators to measure. This eventually formed a measurement system that takes 4 cultural features as the core, 12 sub-dimensions as the intermediate link, and 60 specific indicators as for investigation. Each question in the questionnaire is scored on a scale from 1 to 5,1 being the best and 5 being the worst. Denison conducted a detailed investigation on more than a thousand organizations to prove the validity and reliability of his model. Denison found that each of the cultural traits showed significant positive relationships with a subjective and objective measures of organizational effectiveness such as return on assets, return on investments, product development, sales growth, market share and employee satisfaction.

\subsection{University Organization Culture}

Tierney (1988) is applied the concept of organizational culture from business literature to research in higher education. At the university level, culture can be defined as the values and beliefs of university stakeholders (i.e., administrators, faculty, students, board members and support staff), based on tradition and communicated verbally and non-verbally (Bartell, 2003). Values and beliefs are thought to greatly influence decision-making processes at universities and shape individual and organizational behaviors. Behaviors based on underlying assumptions and beliefs are conveyed through stories, special language and institutional norms (Bartell, 2003; Sporn, 1996).

Sporn (1996) noted that universities are complex organizations and contain multiple variations of organizational culture - at the individual and institutional levels. Different stakeholders, which include students, staff, administrators and professors, have their own priorities and these pose major challenges to university management. Schein (2010) believed that the lack of understanding of organizational culture exhibited by leaders in higher education was inhibiting their ability to lead their institutions to effectively. Tierney (1988) stressed that by having a better understanding of organizational culture, higher education administrators could enhance their daily decision making. 


\subsection{China's University's Organizational Culture}

There are not enough studies done on university organizational culture from the perspectives of education management. University culture and university organizational culture are different, yet related. University culture is a combination of various sub-cultures developed over time (Deal and Kennedy, 1982; Bartell 2003). It includes material culture (infrastructure and facilities), institutional culture (rules \& regulations, operations systems and management systems), and the spiritual culture (identity, values and beliefs).

University organizational culture is defined as a pattern of shared values, beliefs, attitudes and behavior of the members in the organization. It relies on the continuous interactions of top management, administrators, faculty members and students. It shapes the organizational systems and could facilitate or hinder the organization's from achieving its goals (Yilmaz, 2008).

The funders of China's universities are mainly the central and local governments, who provide institutional and financial support to universities. The state will determine the organizational mission and goals of the university it funded. Government support for universities is positively correlated with their control over universities. Under the current system with a high concentration of education administrative authority, it is very difficult to produce a highly autonomous university operation mode dominated by academic authority. Due to the strong governmental influence, universities in China show a lesser degree of differentiation than European or American universities.

\subsection{Organizational Commitment}

Organizational commitment is one of the most important work-related attitudes, which has been studied in management and organizational behavior. Allen \& Meyer (1990) described organizational commitment as a three dimensional concept characterized by affective, continuance and normative dimensions. It is a strong belief in an organization's goals and values, a willingness to exert considerable effort on behalf of an organization and a strong desire to remain a member of the organization (Mowday et al., 1984). Commitment is typically conceived as an individual's psychological bond to the organization, including a sense of job involvement, loyalty and a belief in the values of the organization and a force, which obliged employees to continue in an organization. Commitment is an ongoing process and an attitude, which reflect the loyalty of employees towards the organization (Northcraft and Neale, 1996). Jarfi and Lhamo (2013) noted that more committed employees tend to be better performers. Those employees with higher levels of commitment also showed more motivation in carrying out their tasks (Berberoglu and Secim, 2015). Organizational commitment is an important mediating variable between organizational culture and employee performance (Hakim, 2015). Iriqat (2016) pointed out that organizational commitment played a mediating role between organizational values and job satisfaction (2016). Dadgar, et al., (2013) found that employee commitment and job security working in a friendly environment have a significant positive relationship on employees' intention to stay in the organization.

\subsection{Managers' Performance}

Borman \& Motowidlo (1993) proposed a two-dimensional model consisting of task and performance. Task performance refers to the behavior specified by the organization. It covers the fulfillment of the requirements that are stated in the employment contract. Performance, on the other hand, relates to spontaneous behavior, organizational citizenship behavior, pro-social behavior and dedication to the spirit of organization. It does not contribute directly to organizational performance but enhances the psychological and social aspects of the organization. In this study, we are interested in performance and have adapted Van Scotter \& Motowidlo (1996) performance measurement scale.

Research on the performance of deans and heads of departments is sparse. Effective leaders are required to use problem-solving processes, maintain group effectiveness and develop group identification. The middle level managers play an important role in maintaining the normal operations of universities, participating in the formulation of university strategies, implementing upper decision-making, and innovating the system. They are important intermediaries between top management and lower level staff. As leaders and managers of functional departments, they need to plan their own department short-term, medium and long-term goals. In the face of various problems encountered in their work, they need to thinking creatively, lead staff to contribute their working ideas, and seek solutions to potential problems. 


\section{Research Design}

This study is a quantitative research aimed at assessing the relationship between the organizational culture and middle level managers' performance, with commitment as a mediating variable. Through this research, the authors seek to propose some recommendations to improve the performance of middle level managers. Coldwell and Herbst (2004) noted that the using surveys are very cost-effective. However, it does not permit inferences related to causality. Leedy and Omrod (2005) stressed that quantitative research be used to answer questions about relationships among measured variables with the purpose of predicting and controlling phenomena.

\subsection{Research objective}

The purpose of this paper is to study the impact of organization culture on middle-level managers' performance with commitment as a mediating variable (Figure 1).

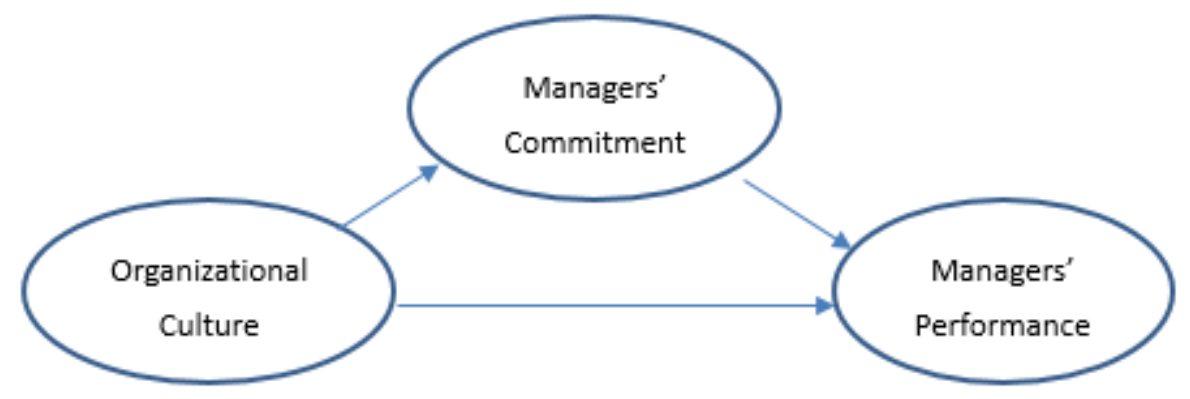

Figure 1. Framework

\subsection{Hypothesis Development}

H1: Organizational culture has a significant influence on commitment;

$\mathrm{H} 2$ : Commitment has a mediating influence between organization culture and performance;

H3: Organizational culture has a significant influence on performance.

\section{Methodology}

\section{Participants}

The data of the study was collected from 55 participants of a Chinese university. The respondents were middle level managers and serve as Dean, Deputy Dean, Director, and Vice Director. A total of 60 questionnaires were distributed, yielding a response rate of $92 \%$.

\section{The instrument}

The questionnaire consisted of a total of 43 questions pertaining to four (4) sections. Section A consisted of 6 questions on the respondents' personal details. For Section B, the authors adapted Denison Organizational Culture Survey Scale. This section consisted of 15 questions on the university culture, in the areas related to involvement, consistency and adaptability.

In Section C, the authors adapted Allen and Meyer Commitment Scale to suit the university environment. This section consisted of 12 questions on employee commitment. In Section D, an adaptation of Van Scotter and Motowidlo performance scale was used for the study. This section consisted of 10 questions on job performance.

The survey items for Section B, C and D were designed as statements measured on the 5-point Likert scale where 1 represents "Strongly Disagree"; 2 represents "Disagree"; 3 represents "Slightly Agree"; 4 represents "Agree"; and 5 represents "Strongly Agree".

Out of the 55 individuals in the study sample, $71 \%$ were men and $21 \%$ were women. From the age perspective, $25 \%$ of the respondents were below 35 years of age, $55 \%$ were between 36 and 45 years old and $20 \%$ were above 46 years of age. The highest percentage of respondents (56\%) hold a Masters degree, followed by $26 \%$ with Bachelor degree and $16 \%$ with Doctoral degree. In terms of administrative position, $44 \%$ hold a Vice Director position, followed by 26\% with Deanship, 22\% Directorship, and 6\% as Vice Dean.

We assessed the hypothesized model with SPSS and structural equation modelling technique using AMOS. 


\section{Results and Discussions}

\subsection{Reliability Analysis}

Table 1. Reliability Statistics

\begin{tabular}{|c|c|c|}
\hline \multicolumn{3}{|c|}{ Reliability Statistics } \\
\hline & $\begin{array}{c}\text { Cronbach's } \\
\text { Alpha Based } \\
\text { on } \\
\begin{array}{c}\text { Cronbach's } \\
\text { Alpha }\end{array}\end{array}$ & \\
\hline .987 & $\begin{array}{c}\text { Standardized } \\
\text { Items }\end{array}$ & N of Items \\
\hline
\end{tabular}

Cronbach's alpha is a commonly used measure to test the extent to which multiple indicators for a latent variable belong together. It ranges from 0 to 1.0. From Table 1, Cronbach's alpha shows a reading of 0.987, which indicates a high level of internal consistency for our scale with this specific sample. The instrument can be deemed as reliable and valid.

The removal of any question would not result in a change in Cronbach's alpha, meaning that the responses in the questionnaire have been reliable. We can also see that the "Corrected Item-Total Correlation" values for all the questions were above 0.65 , indicating a high degree to which one item correlates with the total scores from all the other items that remain.

\subsection{Structural Equation Modelling Analysis}

We use multiple indices of fit including the Root Mean Square Error of Approximation (RMSEA), (Goodness of Fit Index) GFI and Comparative Fit Index (CFI) to evaluate the model's fit to the empirical data.

Table 2. Fitting effect of the model

\begin{tabular}{|l|l|l|l|}
\hline \multicolumn{1}{|c|}{ Index } & \multicolumn{1}{c|}{ RMSEA } & \multicolumn{1}{c|}{ GFI } & \multicolumn{1}{c|}{ CFI } \\
\hline Value & 0.128 & 1.0 & 0.794 \\
\hline Standard & $<0.1$ & $>0.9$ & $>0.9$ \\
\hline Information & Marginal & Good & Marginal \\
\hline
\end{tabular}

The Good of Fit Index (GFI) was created as an alternative to the Chi-Square Test (Joreskog and Sorbom, 1984). It varies from 0 to 1 . A cut-off point of 0.90 has been recommended for the index. From Table 2 , the reading shows that there is a good fit.

The Comparative Fit Index (CFI) compares the existing model fit with a null model, which assumes that the latent variables in the model are, uncorrelated (Byrne, 1998). A standard value of CFI greater than 0.9 indicates a good fit. This index is least affected by sample size. As the reading in Table 2 indicates a value close to 0.9 , there is a marginal fit for CFI.

The Root Mean Square Error of Approximation (RMSEA) was developed by Steiger and Lind (1980). It gives an indication of how well the chosen parameter estimates would fit the population covariance matrix (Byrne, 1998). A value of less than 0.1 indicates a good fit (MacCallum et al, 1996). The reading in Table 2 shows a value close to 0.1 , indicating a marginal fit for RMSEA.

\subsection{Hypothesis Test}

Table 3 below shows the standardized regression weights for paths in the SEM model, along with standard errors, critical rations and p-values.

Table 3. Hypotheses Tests

\begin{tabular}{|c|c|c|c|c|c|}
\hline & Estimates & S.E. & C.R. & P & Hypothesis \\
\hline Commitment <---Culture & 1.415 & .222 & 6.378 & $* * *$ & Supported \\
\hline Performance <--- Commitment & 1.029 & .144 & 7.134 & $* * *$ & Supported \\
\hline Performance <---Culture & -.157 & .175 & -.899 & .369 & Not supported \\
\hline
\end{tabular}

$\mathrm{p}<0.01$ level 
Hypothesis 1: Organizational Culture has an impact on employee commitment.

The results from Table 3 above show that culture has a positive effect on commitment (1.415). Based on Pearson correlation analysis, organizational culture has a positive impact on employee commitment with $r$ values of between 0.471 and 0.827 , significant at the 0.01 level. Therefore, Hypothesis 1 is supported.

Hypothesis 2: Commitment mediates the relationship between organizational culture and employee performance.

The results in Table 2 show that commitment has a positive effect on performance (1.029). The results of Pearson correlation analysis showed that commitment has a positive impact on employee performance with $r$ values of between 0.684 and 0.861 , significant at the 0.01 level. Hypothesis 2 is supported.

The inclusion of the mediating variable of commitment is accompanied by a drop in the values of the regression coefficients representing the direct effects of the culture on performance. The decrease in beta weights from 1.28 to -0.16 indicates that commitment mediates the relationship between culture and performance.

Hypothesis 3: Organizational Culture has an impact on employee performance.

The results in Table 3 show that culture has a negative effect on performance (-.157). The critical ratio of 0.89 with $p$ value of 0.369 is not statistically significant. Therefore, Hypothesis 3 is not supported.

\section{Conclusion}

This research is an empirical study of the impact of organizational culture on middle-level managers' performance under the specific situation of a Chinese university. Our findings in Hypothesis 1 shows that organizational culture has a positive impact on employee commitment. This is in line with previous works of Yiing and Ahmad (2009), Rashid et al. (2003) and Shannawaz and Hazarika (2004).

Hypothesis 2 shows that employee commitment has a positive impact on performance. The empirical results support the findings of Zefeti and Mohamad (2017) that organizational commitment has a significant impact on performance.

Hypothesis 3, however, shows that organizational culture does not have a significant impact on performance, contradicting the results of previous studies done by Zhang (2016) and Roijen et al., (2017). This may possibly be due to the bureaucratic nature of the university as the culture of the university is determined by the top leadership of the university. The Chinese higher education system has traditionally followed the statecontrolled model with universities having little autonomy. While most universities currently enjoy more autonomy than in the past, the President and the Party Secretary are still appointed by the government. The majority of funding comes from the government, which still dictates the major decisions of the universities. As China's higher education sector reforms, it is necessary to redistribute power within the university with new governance structure to meet the rising demands for greater autonomy from academics and administrators. To achieve world-class university status, universities need to focus on three key areas: talent, governance, and resources. Talent encompasses academic talent of professors, researchers, staff and students. Governance include supportive regulatory framework, academic freedom, leadership and culture of excellence. Resources consisted of endownment revenues, budgets and research grants. While formal authority still lies with the President, the concept of shared governance and collegiality should receive greater attention. Universities may have little choice but to slowly reculture themselves if they wish to see improvements in performance of their employees (Yu, 2016). University leadership needs to adopt a new model of shared governance and adapt to an increasingly globalized workplace. A culture of openness and transparency should be encouraged and creative talent should be appreciated for China universities to remain competitive.

\section{Limitations}

This study had focused on one Chinese university, limiting the generalization of results. The authors suggest the need for additional research on managers' performance across China's universities, employing a longitudinal design. It would also be beneficial to investigate other factors that lead to higher performance such as leadership styles, job satisfaction, and managerial experience.

\section{References}

1. Allen, N. J., \& Meyer, J. P. (1990). The measurement and antecedents of affective, continuance and normative commitment to the organization. Journal of Occupational Psychology, 63, 1-18. 
2. Bartell, M. (2003). Internationalization of universities: a university culture-based framework. Higher Education, 45, 43-70.

3. Berberoglu, A. \& Secim, H. (2015). Organizational commitment and perceived organizational performance among health care professionals: Empirical evidence from a private Hospital in Northern Cyprus. Journal of Economics and Behavioral Studies, 7(1), 64-71.

4. Borman, W. C., \& Motowidlo, S. M. (1993). Expanding the criterion domain to include elements of performance. Schmitt,N. and Borman. W.C. (Eds.), San Francisco: Jossey-Bass.

5. Byrne, B.M. (1998). Structural Equation Modeling with LISREL, PRELIS and SIMPLIS: Basic Concepts, Applications and Programming. Mahwah, New Jersey: Lawrence Erlbaum Associates.

6. Coldwell, D. and Herbst, F. (2004). Business Research. Cape Town: Juta and Co Ltd.

7. Dadgar, H., Barahouei, F., Mohammadi, M., Ebrahimi, M., and Ganjali, A. (2013). The Relationship Between Organizational Culture, Job Satisfaction, Organizational Commitment and Intention to Stay of Health Personnel's of Zahedan University of Medical Sciences. World Applied Sciences Journal 21(8), 1220-1228.

8. Deal, T. and Kennedy, A. (1982). Corporate Culture: The Rites and Rituals of Corporate Life. Reading, PA: Addison-Wesley.

9. Denison, D. (1990). Corporate culture and organizational effectiveness, John Wiley \& Son's, New York.

10.Dwivedi, S., Kaushik, S., and Luxmi (2014). Impact of Organizational Culture on Commitment of Employees: An Empirical Study of BPO Sector in India. Vikalpa, 39(3), 77-92.

11.Guan, X., Sun, T., Hou, Y., Liang, Z., Luan, Y. Z., and Fan, L.H. (2014). The relationship between job performance and perceived organizational support in faculty members at Chinese universities: a questionnaire survey. BMC Medical Education. 14(15). Available at: https://doi.org/10.1186/1472-6920-14-5.

12.Hakim, A. (2015). Effect of Organizational Culture, Organizational Commitment to Performance: Study In Hospital Of District South Konawe Of Southeast Sulawesi. The International Journal of Engineering and Sciences. 4(5), 33-41.

13.Iriqat, R.A. (2016). Organizational Commitment Role in Mediating the Impact of the Organizational Culture Dimensions on Job Satisfaction for MFIs' Employees in Palestine. International Journal of Business and Social Science. 7(5), 125-135.

14.Jameson, J. (2011). Changing Leadership Identities: the Role of Trust and Organisational Cultures in a Recessionary UK Higher Education Policy Context, SRHE Higher Educational Policy Network: London Metropolitan University.

15.Jafri, M.H., \& Lhamo, T. (2013). Organizational commitment and work performance in regular and contract faculties of Royal University of Bhutan. Journal of Contemporary Research in Management, 8(2), 47-58.

16.Joreskog, K. G., \& Sorbom, D. (1984). Lisrel VI. Analysis of linear structural relationships by maximum likelihood, instrumental variables, and least squares methods. Mooresville, Indiana: Scientific Software.

17.Leedy, P. D., \& Ormrod, J. E. (2005). Practical research: Planning and Design (8th ed.). Upper Saddle River, NJ: Prentice Hall.

18.Li, P., Liu, Y., Yuan, P., Ju, F. (2017). The Study on the Relationship between University Faculties Job Stress and Organizational Commitment in China, Procedia Computer Science, 122, 642-648.

19.MacCallum, R.C., Browne, M.W., and Sugawara, H., M. (1996). Power Analysis and Determination of Sample Size for Covariance Structure Modeling, Psychological Methods, 1(2), 130-49.

20.McNay, Ian (1995). Universities going international: choices, cautions and conditions, in P. Blok (ed.), Policy and Policy Implementation in Internationalisation of Higher Education, Amsterdam: EAIE.

21.Mowday, R. T., Porter, L. W., \& Steers, R. M. (1984). Employee-organization linkages: the psychology of commitment, absenteeism, and turnover. American Journal of Sociology, 38(6), 19-43.

22.Ministry of Education of the People's Republic of China (2018). Number of Higher Education Institutions. Statistics Department, MOE China.

23.Northcraft, T. \& Neale, H. (1996). Organisation Behaviour. London: Prentice-Hall.

24.Rashid, M.Z.A., Sambasivan, M., and Johari, J. (2003). The influence of corporate culture and organizational commitment on performance. Journal of Management Development, 22(8), 708-728.

25.Ritchie M. (2000). Organizational culture: An examination of its effect on the initialization process and member performance. Southern Business Review, 25, 1-13.

26.Roijen, G., Stoffers, J., and de Vries, R. (2017). Characteristics of High Performance Organization and Knowledge Productivity of Independent Professionals. International Journal of Management and Applied Research, 4(2).

27.Schein, E. H. (2010). Organizational culture and leadership. San Francisco, CA: Jossey-Bass Publishers. 
28.Shamandi, E., Shilong, A.D., Ismail, I.A., Samah, B.A., and Othman, J. (2011). Competencies, Roles and Effective Academic Leadership in World Class University. International Journal of Business Administration, 2(1), 44-53.

29.Shannawaz, M.G. and Hazarika, N. (2004). Organizational commitment and organizational culture: A study of two hospitals in Assam. Journal of Indian Academy of Applied Psychology, 30(1-2), 124-130.

30.Sporn, B. (1996). Managing university culture: an analysis of the relationship between institutional culture and management approaches. Higher Education, 32(1), 41-61.

31.Steiger, J. H., \& Lind, J. C. (1980). Statistically based tests for the number of common factors. Paper presented at the annual meeting of the Psychometric Society, Iowa City, IA.

32.Tierney, W. G. (1988). Organizational culture in higher education: defining the essentials. Journal of Higher Education, 59 (1), 2-21.

33.Van Scotter, J. R., \& Motowidlo, S. J. (1996). Interpersonal facilitation and job dedication as separate facets of performance. Journal of Applied Psychology, 81(5), 525-531.

34.Yiing, L. H., and Ahmad, K.Z.B. (2009). The moderating effects of organizational culture on the relationships between leadership behavior and organizational commitment and between organizational commitment and job satisfaction and performance. Leadership and Organization Development Journal, 30(1), 53-86.

35.Yilmaz, C. \& Ergun, E. (2008). Organizational culture and firm effectiveness: An examination of relative effects of culture traits and the balanced culture hypothesis in an emerging economy. Journal of World Business, 43, 290-306.

36.Yu, S.O. (2016). Reculturing: The key to sustainability of private universities. International Journal of Teaching and Education, 4(4), 88 - 105, doi:10.20472/TE.2016.4.4.005.

37.Zefeiti, S.M.B., and Mohamad, N.A. (2017). The Influence of Organizational Commitment on Omani Public Employees Work Performance. International Review of Management and Marketing, 7(2), 151-160.

38.Zhang, D. (2009). General education reform in Chinese universities: The perspective of organizational culture. Paper presented at the annual meeting of the 53rd Annual Conference of the Comparative and International Education Society, Francis Marion Hotel, Charleston, South Carolina.

39.Zhang, W. J. (2016). Relationship between Organizational Culture Identity and Job Performance of Enterprise Employees. Paper presented at the 3rd International Conference on Advanced Education and Management, Hangzhou, China. 


\section{Appendix}

\section{SURVEY QUESTIONS}

\section{Personal Details}

1) Gender.

2) Age.

3) Education Level.

4) Admin Position.

5) Academic Position.

6) Years of Service.

\section{Organizational Culture}

1) Most employees are highly involved in their work.

2) Decisions are usually made at the level where the best information is available.

3) Information is widely shared so that everyone can get the information he or she needs when it's needed

4) Everyone believes that he or she can have a positive impact.

5) Business planning is ongoing and involves everyone in the process to some degree.

6) Cooperation across different parts of the organization is actively encouraged.

7) People work like they are part of a team.

8) Teamwork is used to get work done, rather than hierarchy.

9) Teams are our primary building blocks.

10) Work is organized so that each person can see the relationship between his or her job and the goals of the organization.

11) Authority is delegated so that people can act on their own.

12) The capability of people is constantly improving.

13) There is continuous investment in the skills of employees.

14) The capabilities of people are viewed as an important source of competitive advantage.

15) Problems seldom arise because we have the skills necessary to do the job.

\section{Managers' Commitment}

1) I would be very happy to spend the rest of my career with this organization.

2) I really feel as if this organization's problems are my own.

3) I do not feel a strong sense of belonging to my organization.

4) I do not feel emotionally attached to this organization.

5) I do not feel like part of the family at my organization.

6) This organization has a great deal of personal meaning for me.

7) Right now, staying with my organization is a matter of necessity as much as desire.

8) It would be very hard for me to leave my organization right now, even if I wanted to.

9) Too much of my life would be disrupted if I decided to leave my organization now.

10) I feel that I have too few options to consider leaving this organization.

11) If I had not already put so much of myself into this organization, I might consider working elsewhere.

12) One of the few negative consequences of leaving this organization would be the scarcity of available alternatives.

\section{Organizational Performance}

1) Encourage others to overcome their differences and get along well.

2) Whether colleagues have problems at work or in life, you can give full encouragement and support

3) You study hard to improve yourself.

4) Even when it is near working hours, it will not rush to complete the work.

5) You can combine personal goals with organizational goals.

6) You value the training opportunities which provided by the organization

7) You work hard to improve your overall quality

8) Leadership is not around, you also can work hard.

9) You can take the initiative to announce the positive news to your external environment and clarify the misunderstanding.

10) I do not mind the Organization's finances. 